\title{
Care From Family Physicians Reported by Pregnant Women in the United States
}

\author{
Katy B. Kozhimannil, $P b D, M P A^{1}$ \\ Patricia Fontaine, MD, MS \\ 'Division of Health Policy and Management, \\ University of Minnesota School of Public \\ Health, Minneapolis-St Paul, Minnesota \\ ${ }^{2}$ HealthPartners Institute for Education and \\ Research, Bloomington, Minnesota
}

Conflicts of interest: authors report none.

\section{CORRESPONDING AUTHOR}

Patricia Fontaine, MD, MS HealthPartners Research Foundation PO Box 1524, MS 21111R 8170 33rd Ave S Bloomington, MN 55425 patricia.l.fontaine@healthpartners.com

\begin{abstract}
PURPOSE We describe the proportion of family physicians providing care of any sort to pregnant women in the United States from 2000 to 2009.

METHODS We used a repeat, cross-sectional design with data from the nationally representative Integrated Health Interview Series (2000-2009) for respondents who reported being pregnant at the time of the survey $(N=3,204)$. Using multivariate logistic regression, we modeled changes over time in pregnant women's reports of care from family physicians. We used interaction terms to test for regional differences in trends.
\end{abstract}

RESULTS Approximately one-third of pregnant women reported having seen or talked to a family physician for medical care during the prior year, a percentage that remained stable for the period of 2000 to 2009 (adjusted odds ratio for annual change $=1.006$ ). Most pregnant women reported care from multiple types of clinicians, including family physicians, obstetrician-gynecologists, midwives, nurse practitioners, and physician assistants. There were regional differences in trends in family physician care; pregnant women in the North Central United States increasingly reported care from family physicians, whereas women in the South reported a decline ( $6.7 \%$ annual increase vs $4.7 \%$ annual decrease, $P \geq .001)$.

CONCLUSIONS Trends in family medicine care for pregnant women have remained steady for the nation as a whole, but they differ by region of the United States. Most pregnant women reported care from multiple clinicians, highlighting the importance of care coordination for this patient population.

Ann Fam Med 2013;350-354. doi:10.1370/afm.1510.

\section{INTRODUCTION}

$\mathrm{F}$ amily physicians are important providers of care for reproductive-age women, and the breadth of the specialty includes care before, during, and after pregnancy. ${ }^{1,2}$ Primary care, family planning, preconception, and prenatal care contribute to the health and well-being of women during the perinatal period and beyond. ${ }^{3}$

The proportion of women's preventive health visits conducted by family physicians remained stable from 1995 to 2007, accounting for $20 \%$ of such visits overall and $28 \%$ in nonmetropolitan areas. ${ }^{4}$ The role of family physicians as providers of maternity-related care, however, has steadily declined. ${ }^{5,6}$ Family physicians provided $12 \%$ of prenatal visits in 1995 to 1996 and only $6 \%$ in 2003 to $2004 .{ }^{5}$ In $2006,7 \%$ of women had a family physician attend their delivery. ${ }^{7}$ As of 2009 , there were notable regional differences in maternity care, with family physicians in the North Central and Pacific regions more likely provide hospital obstetrics (22\% and 33\%, respectively) compared with family physicians in the Mid- and South Atlantic (5\% and $8 \%$, respectively). ${ }^{8}$

Women receive medical care from many types of clinicians during the perinatal period, including family physicians, obstetrician-gynecologists, midwives, other specialists, and midlevel clinicians. The extant literature contains descriptions of trends in provision of prenatal and intrapartum 
care by family physicians but does not quantify the number of pregnant women who have family doctors. This analysis describes the proportion of family physicians providing medical care of any sort to pregnant women in the United States and examines trends over time and by geographic region.

\section{METHODS}

\section{Data and Study Population}

Data came from the Integrated Health Interview Series (IHIS), a harmonization of data from the US National Health Interview Surveys (NHISs), which are conducted annually by the US Centers for Disease Control and Prevention (CDC) among a populationbased, representative sample of noninstitutionalized Americans. ${ }^{9,10}$ Detailed information regarding this data source, the CDC's survey methodology, and the data harmonization process is available on the IHIS Web site (http://www.ihis.us). IHIS data have been used to describe longitudinal trends in many clinical and policy areas. ${ }^{10-14}$ We analyzed survey findings from 2000 to 2009 for all female respondents aged 18 to 49 years who reported being pregnant at the time of the survey $(\mathrm{N}=3,204)$.

\section{Variable Measurement}

We constructed a proxy measure of family physician care (which was not ascertained directly) as whether a woman had "seen or talked to a general doctor who treats a variety of illnesses (a doctor in general practice, family medicine, or internal medicine)" during the prior 12 months and that this general doctor "treats both children and adults." Survey questions asked about care received by the respondent in the past 12 months, so this measure may include primary care visits in addition to prenatal and maternity-related services. Women also reported whether they received care from an obstetrician-gynecologist or from a midlevel clinician (midwife, nurse practitioner, or physician assistant). A broad range of sociodemographic characteristics are self-reported ${ }_{i}$ region is based on the respondent's place of residence, ascertained during survey processing.

\section{Statistical Analysis}

Using data for 3,204 pregnant women who responded to NHIS questionnaires from 2000 to 2009, we calculated unweighted descriptive statistics and conducted logistic regression using population-representative weights and adjusted for survey design features. Regression models included variables for year and multiple sociodemographic characteristics. Health insurance and "other" race were dropped from the final model because of collinearity or small sample size. To investigate whether annual trends differed by region, we added interaction terms between year and region. Results from these models, along with mean covariate values, were used to calculate the predicted probability of reporting family physician care for an average woman in each region.

This study was granted exemption from review by the Institutional Review Board at the University of Minnesota.

\section{RESULTS}

Slightly more than one-third of pregnant women in our aggregated 10-year sample reported care from a family physician during the prior year (Table 1). Approximately one-fourth were Hispanic and 13\% were black; one-third were under age 25 years. The majority of pregnant women receiving care from family physicians had a high school education or less, and one-half were working. Seventeen percent were low-income; $10 \%$ were uninsured, $30 \%$ had Medicaid, and 55\% had private coverage. Results from logistic regression models are shown on the right side of Table 1 as adjusted odds ratios (AORs) and 95\% confidence intervals. There were no significant changes in annual trends in family physician care $(\mathrm{AOR}=1.006)$. Although $34.4 \%$ of pregnant women reported care from family physicians, just $3.8 \%$ saw family physicians alone (Table 2 ). The majority $(64.8 \%)$ of pregnant women reported care from multiple clinicians during the past year. The proportion of pregnant women reporting care from family physicians and other clinicians remained steady over time (results not shown).

Although overall trends in family physician care were steady, there were significant regional differences. We found an increasing trend in family physician care in the North Central region (6.7\% annual increase), steady trends in the Northeast and West, and a decline in the South (4.7\% annual decrease). Figure 1 displays these findings using model-based predicted probabilities from the 2000-2009 study period, extrapolated by region from 2010 to 2015 and assuming unchanging trends in care for the "average" woman: aged 27 years, white, married, working, US-born citizen with a high school education. In this model, by 2015, more than $60 \%$ of all pregnant women in the North Central region will have consulted a family physician for her medical care during the prior year.

\section{DISCUSSION}

Even though provision of maternity care by family physicians has decreased during the past decade, a 
substantial and steady proportion of pregnant women $(34.4 \%)$ received care from a family physician, underscoring the importance of family physicians as providers of clinical services for childbearing women, before and during pregnancy. ${ }^{3}$ Family physicians need to be familiar with preconception care and with the physiologic changes and common complications of pregnancy, even if they are not the clinician solely or primarily responsible for prenatal care.

\begin{tabular}{|c|c|c|c|}
\hline Characteristic & $\begin{array}{c}\text { Did Not See } \\
\text { Family Physician } \\
\text { No. }(\%)^{a}\end{array}$ & $\begin{array}{l}\text { Saw Family } \\
\text { Physician } \\
\text { No. }(\%)^{a}\end{array}$ & $\begin{array}{l}\text { Reporting Care From } \\
\text { a Family Physician } \\
\text { AOR }(95 \% \text { Cl) }\end{array}$ \\
\hline Total & $2,103(65.6)$ & $1,101(34.4)$ & - \\
\hline $\begin{array}{l}\text { Annual trend over time } \\
(2000-2009)\end{array}$ & - & - & $1.006(0.996-1.016)$ \\
\hline \multicolumn{4}{|l|}{ Race/ethnicity } \\
\hline Hispanic & $667(31.7)$ & $268(24.3)$ & $0.762(0.501-1.159)$ \\
\hline Black & 391 (18.6) & $145(13.2)$ & $0.485(0.366-0.643)$ \\
\hline White & $860(40.9)$ & $607(55.1)$ & Ref \\
\hline Other & $185(8.8)$ & $81(7.4)$ & $N A^{b}$ \\
\hline \multicolumn{4}{|l|}{ US Region } \\
\hline Northeast & $372(17.7)$ & $141(12.8)$ & $0.611(0.494-0.757)$ \\
\hline North Central & 405 (19.3) & $293(26.6)$ & Ref \\
\hline South & 777 (36.9) & $413(37.5)$ & 0.821 (0.667-1.009) \\
\hline West & $549(26.1)$ & $254(23.1)$ & $0.730(0.598-0.891)$ \\
\hline Age, $y^{c}$ & & & $0.980(0.968-0.991)$ \\
\hline$<25$ & $628(29.9)$ & $385(35)$ & - \\
\hline $25-29$ & $625(29.7)$ & $312(28.3)$ & - \\
\hline $30-34$ & $529(25.2)$ & $242(22)$ & - \\
\hline$\geq 35$ & $321(15.3)$ & $162(14.7)$ & - \\
\hline \multicolumn{4}{|l|}{ Demographics } \\
\hline Married & $1,390(66.1)$ & $725(65.8)$ & $0.882(0.814-0.955)$ \\
\hline Working & $1,028(48.9)$ & $551(50)$ & $0.967(0.586-1.134)$ \\
\hline US citizen & $1,640(78)$ & $954(86.6)$ & $1.069(0.868-1.317)$ \\
\hline US born & $1,493(71)$ & $907(82.4)$ & $1.419(0.932-2.160)$ \\
\hline \multicolumn{4}{|l|}{ Education } \\
\hline Less than high school & $504(24)$ & $214(19.4)$ & Ref \\
\hline High school degree & $1,005(47.8)$ & $564(51.2)$ & $1.155(0.929-1.437)$ \\
\hline College degree & $340(16.2)$ & $199(18.1)$ & $1.288(1.021-1.626)$ \\
\hline Graduate degree & $169(8)$ & $92(8.4)$ & $1.133(1.023-1.255)$ \\
\hline \multicolumn{4}{|l|}{$\begin{array}{l}\text { Income, health, and } \\
\text { health insurance }\end{array}$} \\
\hline $\begin{array}{l}\text { Family income less } \\
\text { than FPL }\end{array}$ & 399 (19) & $193(17.5)$ & $1.123(0.754-1.672)$ \\
\hline Poor or bad health & $101(4.8)$ & $65(5.9)$ & $1.446(1.310-1.596)$ \\
\hline Currently uninsured & $309(14.7)$ & $110(10)$ & $N A^{b}$ \\
\hline $\begin{array}{l}\text { Currently publicly } \\
\text { ensured (Medicaid) }\end{array}$ & $612(29.1)$ & 329 (29.9) & $N A^{b}$ \\
\hline $\begin{array}{l}\text { Currently privately } \\
\text { ensured }\end{array}$ & $1,067(50.7)$ & $603(54.8)$ & $N A^{b}$ \\
\hline
\end{tabular}

In the United States, women typically seek care from multiple clinicians to meet their medical needs. ${ }^{15-18}$ This study confirms that pregnant women see multiple clinicians during the perinatal period. Because clinical circumstances may necessitate specialized care, and patients may shift among clinicians, care coordination is a clear need for pregnant women ${ }^{19}$ and has been shown to improve outcomes, especially for underserved women. ${ }^{20,21}$ One strategy that holds promise for improving care coordination is the patient-centered medical home model $(\mathrm{PCMH})$ advocated by the American Academy of Family Physicians and other professional societies. PCMH models have yet to be widely implemented for maternity care, but have met with early successes in other clinical areas..$^{22,23}$ Clinical maternity outcomes have historically been similar among low-risk patients of family physicians, midwives, and obstetricians, and emerging evidence suggests that midwifery models of care may improve outcomes for low-risk women. ${ }^{24-26} \mathrm{Col}$ laborative practice models have recently generated enthusiasm for improving care coordination and meeting maternity-related health care needs. ${ }^{27,28}$ Most collaborative models in the United States have combined midwifery and obstetric practices, and-indeedpregnant women increasingly report care from such a combination of clinicians ${ }^{29}$ Collaborative maternity practices that include family physicians and other clinicians have met with early success and may warrant further exploration. ${ }^{30,31}$ Additional research is needed to evaluate choices, outcomes, costs, and women's satisfaction with care in various care delivery models.

Although future investigations may shed light on best practices, it is important that all pregnant women have access to care. Our analysis revealed that $7.8 \%$ of pregnant women reported that they had not seen a clinician 


\section{Table 2. Clinicians From Whom US Pregnant Women Reported Care in the Prior Year, 2000-2009 $(\mathrm{N}=3,204)$}

\begin{tabular}{lc}
\hline Clinician & No. (\%) \\
\hline Any care from a clinician & $2,953(92.2)$ \\
Family physician & $1,101(34.4)$ \\
Obstetrician & $2,750(85.8)$ \\
Midwife, NP, or PA & $927(28.9)$ \\
Care from only 1 type of clinician & $1,128(35.2)$ \\
Family physician only & $121(3.8)$ \\
Obstetrician only & $962(30.0)$ \\
Midwife, NP, or PA only & $45(1.4)$ \\
Care from multiple types of clinicians & $2,076(64.8)$ \\
Family physician and obstetrician & $542(16.9)$ \\
Family physician and midwife, NP, or PA & $385(12.0)$ \\
Obstetrician and midwife, NP, or PA & $845(26.4)$ \\
Family physician, obstetrician, and midwife, NP, & $348(10.9)$ \\
$\quad$ or PA & \\
\hline NP = nurse practitioner; PA = physician assistant. & \\
\hline
\end{tabular}

during the past year (Table 2). Our findings regarding regional differences raise questions about ongoing changes in the family physician's scope of practice, particularly in the South, where pregnant women are reporting decreases in care from family physicians. Factors associated with family medicine specialty choice include female sex, rural background, and an interest in obstetric care, ${ }^{32,33}$ which may help to cultivate the family physician workforce in places with greatest needs.

The analysis has important limitations. The survey did not ask about the status or gestational age of the pregnancy, delivery attendant, or about timing or reasons for visits with different types of clinicians, so we are unable to determine whether women consulted family physicians for preconception care, general primary care, prenatal care, or other health services. No information on clinician practice models was collected in the survey. Finally, our proxy definition for family physician care is limited by the survey questions and may possibly have misclassified general practitioners or internal medicine physicians who also see pediatric patients as family physicians.

Given that pregnant women were likely to report care from multiple clinicians, coordinating preconception, prenatal, and postpartum care is essential to ensure that relevant health information is shared, screenings and necessary follow-up are provided, and high-quality care is delivered to women through the reproductive years and beyond.

To read or post commentaries in response to this article, see it online at http://www.annfammed.org/content/11/4/350.

Key words: family practice; pregnancy; maternal health services; primary health care; women's health services

Submitted March 1, 2012; submitted, revised, November 26, 2012; accepted December 10, 2012.

Funding support: Dr Kozhimannil's work in this project was supported by the Building Interdisciplinary Research Careers in Women's Health Grant (\# K12HD055887) from the Eunice Kennedy Shriver National Institutes of Child Health and Human Development (NICHD), the Office of Research on Women's Health, and the National Institute on Aging, National Institutes of Health $(\mathrm{NIH})$, administered by the University of Minnesota Deborah E. Powell Center for Women's Health.

\section{Figure 1. Predicted probability that an average pregnant woman (aged 27 years, white, married, working, uS-born citizen with high school education) reports having seen a family physician in the prior year, by US region.}

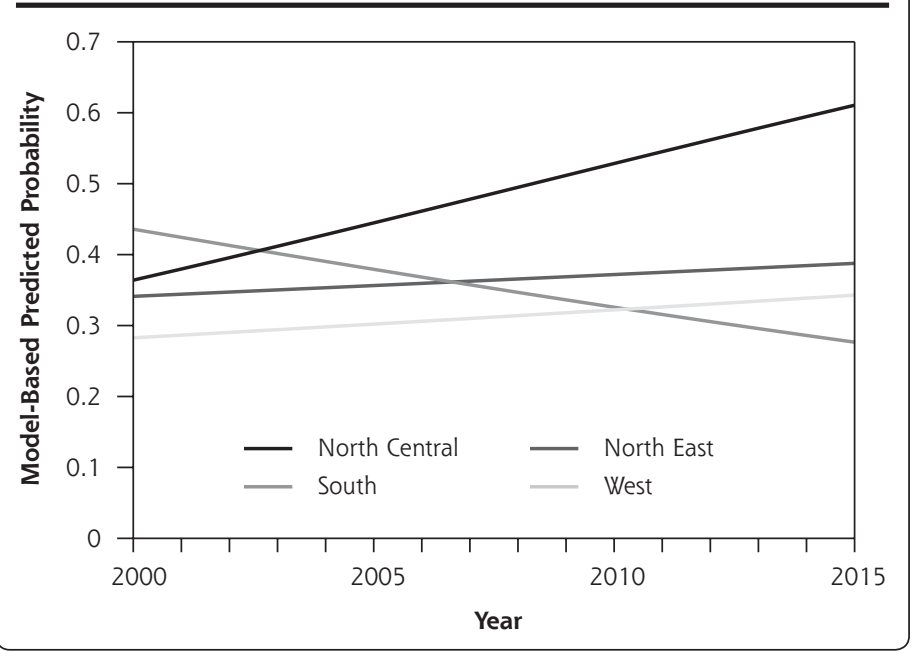

Disclaimer: The content is solely the responsibility of the authors and does not necessarily represent the official views of the NICHD or $\mathrm{NIH}$.

Acknowledgments: The authors gratefully acknowledge helpful input provided by Shailendra Prasad, MD, MPH.

\section{References}

1. Berns SD, Kott A, eds. Toward Improving the Outcome of Pregnancy III: Enhancing Perinatal Health Through Quality, Safety and Performance Initiatives. White Plains, NY: March of Dimes National Foundation; 2010.

2. Phillips WR, Haynes DG. The domain of family practice: scope, role, and function. Fam Med. 2001;33(4):273-277.

3. Johnson K, Posner SF, Biermann J, et al; CDC/ATSDR Preconception Care Work Group; Select Panel on Preconception Care. Recommendations to improve preconception health and health care-United States. A report of the CDC/ATSDR Preconception Care Work Group and the Select Panel on Preconception Care. MMWR Recomm Rep. 2006;55(RR-6):1-23.

4. Cohen D, Coco A. Trends in the provision of preventive women's health services by family physicians. Fam Med. 2011;43(3):166-171. 
5. Cohen D, Coco A. Declining trends in the provision of prenatal care visits by family physicians. Ann Fam Med. 2009;7(2):128-133.

6. Tong STC, Makaroff LA, Xierali IM, et al. Proportion of family physicians providing maternity care continues to decline. J Am Board Fam Med. 2012;25(3):270-271.

7. Declercq E, Sakala C, Corry M, Applebaum S. Listening to Mothers II: Report of the Second National U.S. Survey of Women's Childbearing Experiences. New York, NY: Childbirth Connection; 2006.

8. American Academy of Family Physicians. Performance of obstetrics in hospital practices of family physicians by census division, September 2009. http://www.aafp.org/online/en/home/aboutus/specialty/ facts/34.htm. Accessed Jan 4, 2012.

9. Minnesota Population Center. Integrated Health Interview Series: Version 3.0. Minneapolis: MN: Population Center and State Health Access Data Assistance Center, University of Minnesota; 2010.

10. Johnson PJ, Blewett LA, Ruggles S, Davern ME, King ML. Four decades of population health data: the integrated health interview series as an epidemiologic resource. Epidemiology. 2008;19(6): 872-875.

11. Blewett LA, Johnson PJ, Mach AL. Immigrant children's access to health care: differences by global region of birth. J Health Care Poor Underserved. 2010;21(2)(Suppl):13-31.

12. Chou CF, Johnson PJ. Health disparities among America's health care providers: evidence from the Integrated Health Interview Series, 1982 to 2004. J Occup Environ Med. 2008;50(6):696-704.

13. Yu TC, Chou CF, Johnson PJ, Ward A. Persistent disparities in pap test use: assessments and predictions for Asian women in the U.S., 1982-2010. J Immigr Minor Health. 2010;12(4):445-453.

14. Chou CF, Johnson PJ, Ward A, Blewett LA. Health care coverage and the health care industry. Am J Public Health. 2009;99(12):2282-2288.

15. Clancy CM, Massion CT. American women's health care. A patchwork quilt with gaps. JAMA. 1992;268(14):1918-1920.

16. Henderson JT, Weisman CS, Grason H. Are two doctors better than one? Women's physician use and appropriate care. Womens Health Issues. 2002;12(3):138-149.

17. Lentz GM, Ayala L, Eckert LO. A comprehensive women's health care center: are gynecologists offering primary care? Am J Obstet Gynecol. 2006;194(6):1660-1666; discussion 1666-1667.

18. Scholle SH, Chang JC, Harman J, McNeil M. Trends in women's health services by type of physician seen: data from the 1985 and 1997-98 NAMCS. Womens Health Issues. 2002;12(4):165-177.

19. Carter MC, Corry M, Delbanco S, et al; Transforming Maternity Care Vision Team. 2020 vision for a high-quality, high-value maternity care system. Womens Health Issues. 2010;20(1)(Suppl):S7-S17.
20. Lu MC, Kotelchuck M, Hogan VK, Johnson K, Reyes C. Innovative strategies to reduce disparities in the quality of prenatal care in underresourced settings. Med Care Res Rev. 2010;67(5) (Suppl):198S-230S.

21. Van Dijk JW, Anderko L, Stetzer F. The impact of Prenatal Care Coordination on birth outcomes. J Obstet Gynecol Neonatal Nurs. 2011:40(1):98-108.

22. Reid RJ, Fishman PA, Yu O, et al. Patient-centered medical home demonstration: a prospective, quasi-experimental, before and after evaluation. Am J Manag Care. 2009;15(9):e71-e87.

23. Nielsen M, Langner B, Zema C, Hacker T, Grundy P. Benefits of Implementing the Primary Care Patient-Centered Medical Home: A Review of Cost and Quality Results, 2012. Washington, DC: PatientCentered Primary Care Collaborative; 2012.

24. Hueston WJ, Applegate JA, Mansfield CJ, King DE, McClaflin RR. Practice variations between family physicians and obstetricians in the management of low-risk pregnancies. J Fam Pract. 1995;40(4): 345-351.

25. Hueston WJ, Rudy M. A comparison of labor and delivery management between nurse midwives and family physicians. J Fam Pract. 1993;37(5):449-454.

26. Hatem M, Sandall J, Devane D, Soltani H, Gates S. Midwife-led versus other models of care for childbearing women. Cochrane Database Syst Rev. 2008;(4):CD004667.

27. Downe S, Finlayson K, Fleming A. Creating a collaborative culture in maternity care. J Midwifery Womens Health. 2010;55(3):250-254.

28. Waldman RN, Kennedy HP. Collaborative practice between obstetricians and midwives. Obstet Gynecol. 2011;118(3):503-504.

29. Kozhimannil KB, Avery MD, Terrell CA. Recent trends in clinicians providing care to pregnant women in the United States. J Midwifery Womens Health. 2012;57(5):433-438.

30. Pecci CC, Hines TC, Williams CT, Culpepper L. How we built our team: collaborating with partners to strengthen skills in pregnancy, delivery, and newborn care. J Am Board Fam Med. 2012;25(4): 511-521.

31. Price D, Howard M, Shaw E, Zazulak J, Waters H, Chan D. Family medicine obstetrics. Collaborative interdisciplinary program for a declining resource. Can Fam Physician. 2005;51:68-74.

32. Bennett KL, Phillips JP. Finding, recruiting, and sustaining the future primary care physician workforce: a new theoretical model of specialty choice process. Acad Med. 2010;85(10)(Suppl):S81-S88.

33. McGaha AL, Schmittling GT, DeVilbiss AD, Pugno PA. Entry of US medical school graduates into family medicine residencies: 20082009 and 3-year summary. Fam Med. 2009;41(8):555-566. 